\title{
A method for describing and modelling of within-ring wood density distribution in clones of three coniferous species
}

\author{
Miloš IVkOvića,b*, Philippe ROZENBERG ${ }^{\mathrm{a}}$ \\ a INRA, Centre de Recherches d'Orléans, Unité d'Amélioration, Génétique et Physiologie Forestières, France \\ b Current address: ENSIS Tree Improvement and Germplasm, CSIRO Forestry and Forest Products, PO Box E4008, Kingston ACT 2604, Australia
}

(Received 5 January 2004; accepted 15 September 2004)

\begin{abstract}
Wood density within growth rings was examined and modelled for clones of three coniferous species: Norway spruce, Douglas fir, and maritime pine. Within-ring density measurements obtained by X-ray scanning were represented as a frequency distribution. The distribution was described using both moment-based and non-parametric (robust) statistics and its sample quantiles were modelled using the generalised lambda distribution. In Norway spruce the frequency distribution of wood density was unimodal and asymmetric (i.e. positively skewed), whereas in Douglas fir and maritime pine, the distribution was bimodal (i.e. mixture of two skewed distributions, corresponding to earlywood and latewood ring zones). In all three species, analyses of covariance revealed that, after adjustment for ring width or mean ring density, there was still significant $(p<0.01)$ clone variability in within-ring frequency distribution parameters (i.e. clones with similar growth rate or mean density had different within-ring structure).
\end{abstract}

Norway spruce / Douglas-fir / maritime pine / wood density / modelling

Résumé - Une méthode pour description et modélisation de la distribution de densité intra-cerne du bois parmi les clones de trois espèces de conifères. La densité du bois dans les cernes de croissance a été examinée et modélisée pour les clones de trois espèces de conifères : épicéa commun, sapin Douglas, et pin maritime. Les mesures de densité intra-cerne, obtenues par densitométrie aux rayons-X, ont été représentées sous forme de distribution de fréquence. La distribution a été décrite en utilisant des statistiques paramétriques (basés sur les moments) et non-paramétriques, et ses quantiles ont été modélisés en utilisant la distribution généralisée de lambda. Pour l'épicéa la distribution de fréquence de la densité du bois était uni-modale et asymétrique (coeff. d'asymétrie positif), tandis que dans le Douglas et le pin maritime, la distribution était bimodale (c-à-d mélange de deux distributions asymétriques, correspondant aux zones de cerne du bois initial et du bois final). Dans chacune des trois espèces, les analyses de covariance ont indiqué que, après ajustement pour la largeur de cerne ou la densité moyenne de cerne, il restait une variabilité significative entre clones $(p<0,01)$ des paramètres de distribution de fréquence intra-cerne (c-à-d des clones avec un taux de croissance ou une densité moyenne semblable, avaient une structure intra-cerne différente).

épicéa / douglas / pin maritime / densité du bois / modélisation

\section{INTRODUCTION}

Within a tree, wood density varies from pith to bark and from butt to top, however, most variation in wood density lies within growth rings. In temperate climates, wood formation is a periodic process. Cambium activity starts in spring and stops at the end of summer or at the beginning of autumn. During the active period, the cambium produces a number of xylem cells of different shapes and sizes. Two classes of cells, earlywood and latewood, are usually defined to explain the apparent ring structure. Those two classes are usually used to account for withinring density variation. They can also be used to examine the relationship between growth and wood density within individual rings. By separating a ring into different wood density classes, its total density can be decomposed into the sum of densities of each class multiplied by its proportion [23]. Wide rings can conceivably have an extra component of less dense earlywood, causing a negative correlation between ring width and density in some conifers. If the proportion of latewood is small, as in spruce (Picea sp.), total ring density is largely determined by the density of earlywood [15, 22, 26, 27]. In Douglas fir and pines, the negative correlation between growth and wood density is generally less pronounced than in spruce, and the causal relationships are not so clear [3, 18, 28, 30].

Availability of X-ray and anatomical imaging data make it possible to look at complete sequence of within-ring wood production (i.e. to trace a density profile). Such a profile represents a complete time sequence of wood production and it can be

\footnotetext{
* Corresponding author: Milosh.Ivkovich@csiro.au
} 
Ns
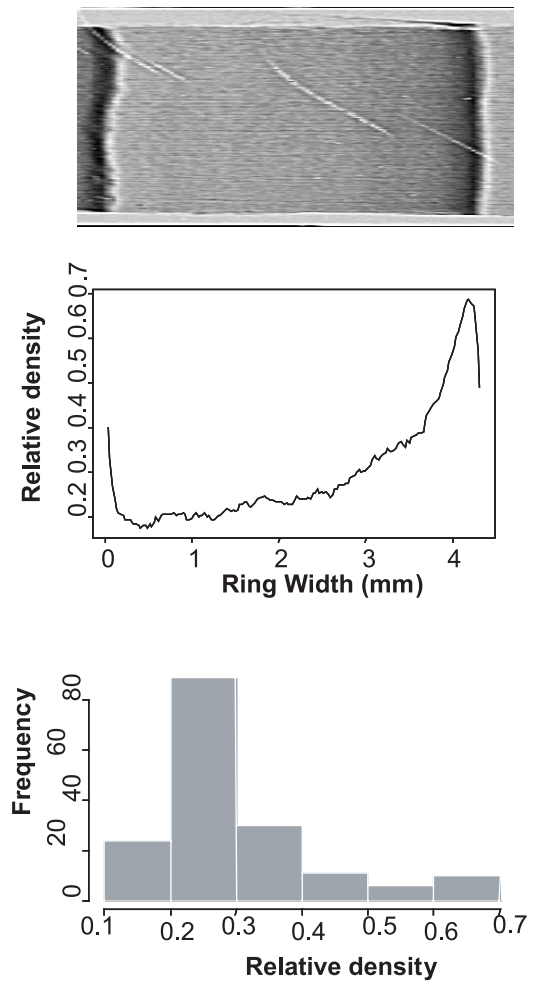

Df
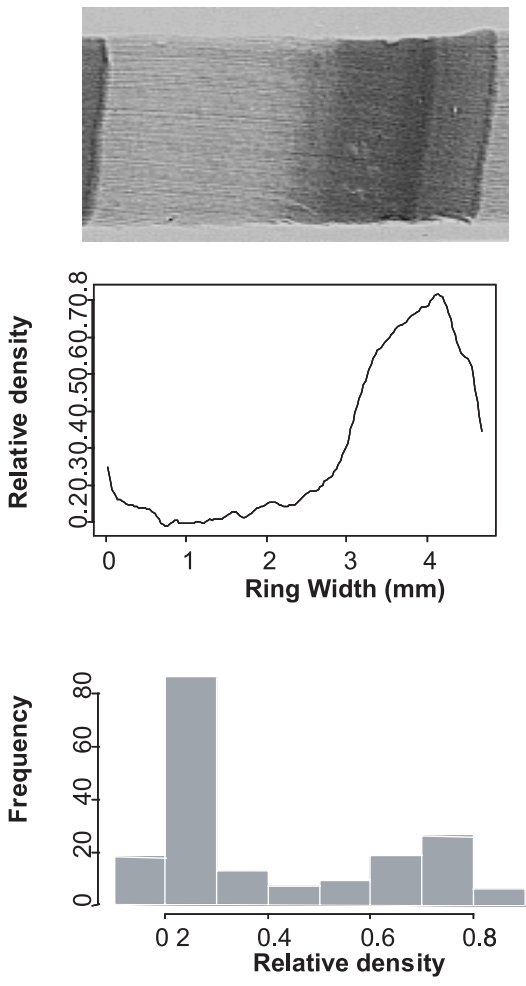

Mp
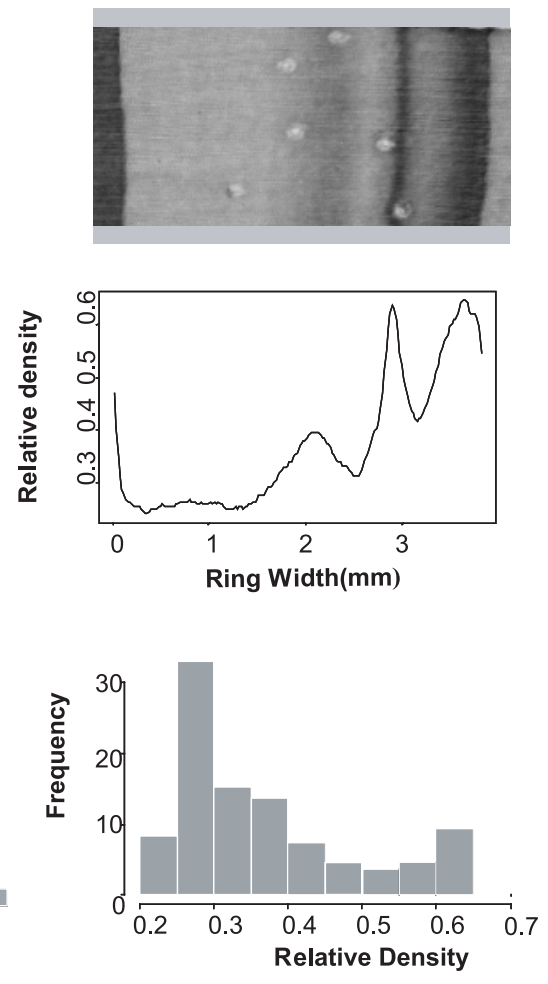

Figure 1. Typical wood structure, density profiles and frequency class histograms for Norway spruce (Ns), Douglas fir (Df) and Maritime pine (Mp).

modelled using an exponential or polynomial function [10]. However, high order polynomials are usually needed to describe a profile and derived parameters are difficult to interpret. Other ways of describing density profiles have also been proposed, such as multiple classes with variable boundaries, wavelets, and the "profile energy" [16]. In this study, we examine the empirical frequency class distribution obtained from within-ring density measurements without considering the time sequence of wood production (Fig. 1).

Although the wood production sequence in time can be very valuable for studying relationship between cambial activity and climate, it may be irrelevant for modelling end- product properties. The end-users of wood, for example, in the pulp and paper production, could benefit from knowing the complete distribution of fibre properties rather than only the average values [7, 9]. Within-ring frequency distributions of various fibre characteristics were also used for comparing wood of different ages in radiata pine [2]. The frequency distributions may not be symmetric and unimodal, and statistics such as mean and standard deviation may not provide for their most accurate description. The shape of the frequency distribution can be described more accurately by other (robust) statistical parameters, and modelled by a known distribution function.

The main objective of this study was to examine alternative ways to describe and model within-ring distribution of wood density for plantation grown clones of three coniferous species:
Norway spruce (Picea abies L.), Douglas fir (Pseudotsuga menziesii Douglas) and maritime pine (Pinus pinaster Ait.). It was supposed that some alternative descriptive statistics might have closer correlation with growth rate and more variability among clones than the classical ones (e.g. mean ring density, latewood percentage etc.). The specific objectives were the following:

(i) to estimate descriptive statistical parameters and to model within-ring density frequency distribution using a known (i.e. generalised $\lambda$ ) distribution,

(ii) to estimate correlation between growth rate and the position and shape of the density distribution,

(iii) to determine contribution of genetic causes to the variability in the distribution, and to examine the potential utility of using parameters describing within-ring distribution of wood density in clone selection and deployment.

\section{MATERIALS AND METHODS}

\subsection{Plant material}

Norway spruce (Ns) clone test used for this study was established in 1978 at two sites in southern Sweden: Hermanstorp and Knutstorp. At Hermanstorp 182 trees representing 43 clones and at Knutstorp 125 trees representing 30 clones were planted. Twenty clones were 
common to both sites. In the fall of 1997, 299 trees representing 53 clones were felled. The sampling was done randomly with restriction that all common clones should be included and the other clones should have at least four living trees left in the trial. Discs were taken at breast height $(1.3 \mathrm{~m})$ from each tree for assessment of wood properties. However, for various reasons data for only 45 clones were kept for the final analyses.

Douglas fir (Df) clone test was established in 1978 at a site in the forest district of Kattenbuehl, Lower Saxony, Germany. The clones were propagated from seedlings grown at Escherode (Germany), originating from a large seed collection made in Canada (British Columbia) and the USA (Washington and Oregon, west of the Cascade range). The test was planted using rooted cuttings from the best seedlings of the best provenances (selection based on survival and growth). The best $20 \%$ of clones were selected for planting. In the spring of 1998, when trees were 24 years old, 50 clones were sampled from the clonal test with the objective of maximising the variation in diameter and depth of pilodyn pin penetration within the sample (pilodyn is a tool for indirect assessment of wood density). Sampling was done from the extremes of distributions for the two traits and is likely to over-estimate the genetic variation in wood properties. One radial increment core was collected at breast height from 179 trees (3-5 trees per clone).

Maritime pine $(\mathrm{Mp})$ clone test used in this study was established in 1987 in Robinson, Gironde, France. The clones come from controlled crossing of parents selected for their growth vigour and straightness. In 2000, when trees were 13 years old, increment cores at breast height were collected with the objective of wood quality assessment. Altogether 42 clones with four trees per clone were sampled.

$\mathrm{X}$-ray micro-density measurements were taken on sample strips cut from cross-sectional discs or cores. The within-ring density data was recorded at a rate of one data point each $4.25 \mathrm{~m} \mu$ distance. Frequency distributions of wood density were obtained for 3 growing seasons (i.e. 3 ring ages), for Ns 1994-1996 (age 16-18), for Df 1995-1997 (age 21-23) and for Mp 1996-1998 (age 9-11).

\subsection{Statistics describing within-ring distribution of wood density}

Frequency distribution of multiple within-ring density classes was first visually examined using histograms. Some distribution features were obvious, although a histogram representation is not optimal because of the arbitrary class separation [1]. In Norway spruce the frequency distribution of wood density appeared to be unimodal and asymmetric (i.e. a positively skewed distribution). Therefore, for Norway spruce, only one density distribution was used in the subsequent analyses. On the other hand, for Douglas fir and maritime pine, species which have an abrupt transition between early- and late-wood zones, the distribution appeared to be bimodal (i.e. mixture of two skewed distributions). In the latter case, we estimated the probability density function for those two distributions combined. We then separated the two distributions at the point of their overlap. This method is different from commonly used methods for earlywood (EW) and latewood (LW) separation. Nevertheless, the two distributions of low and high density corresponded to EW and LW ring zones as defined by classical methods: there was generally a good agreement when classical density parameters (zone width and its minimum, average and maximum density) were calculated for EW and LW zones separated either by the method based on the frequency distribution and by the "Average of Extremes" method [23]. For Douglas fir correlation coefficients were high $\left(r>0.99, p_{(r=0)}<0.01\right)$. For maritime pine the agreement was not as good, especially in certain rings with multiple peaks $(r<0.80$, $\left.p_{(r=0)}<0.01\right)$. For such rings the placement of the EW/LW boundary was problematic anyhow. Low and high density distributions in Douglas fir and maritime pine were treated separately in the subsequent analyses.
The within-ring density distributions were described using the following statistical parameters: mean $(\mu)$, standard deviation $(s d)$, and the coefficients of skewness ( $k k w)$ and kurtosis (kur). Those statistics provide a moment based summary of a data set, but the coefficient $s k w$ is sensitive to outlying observations and kur is even less robust. Furthermore, $k u r$ depends on both central and tail data and very different shaped data can lead to the same kur [5].

Quantile (or percentile) based coefficients produce parallel, but generally more robust measures of the shape of a distribution [5]. Based on minimum ( $\mathrm{min}$ ), lower quartile $(l q)$, median (med), upper quartile $(u q)$, maximum ( $\max$ ) a quantile summary for a distribution is provided by the following derived parameters:

- interquartile range: $q r=u q-l q$;

- quartile difference: $q d=l q+u q-2 m e d$ ( $q d=0$ for a symetric distribution);

- Galtion's skewness coeficient: $g=q d / i q r$ (a positive $g$ indicates a distribution skewed to the right);

- quantile kurtosis: $q k u r=\left[\left(e_{7}-e_{5}\right)+\left(e_{3}-e_{1}\right)\right] / i q r$

(which makes use of octiles $e_{j}=q_{(j / 8)}$ ).

For more precise distribution comparisons shape indices can be estimated over a range of proportions $(p)$. For a symmetric distribution difference between some upper and lower $p$-deviations will be equal to zero: $p d_{(p)}=u p_{(p)}+l p_{(p)}-2 m e d=0$. Skewness can be evaluated over a range $0<p<0.5$ and the maximum gives an overall measure of asymmetry as:

- quantile skewness: $q s k w_{(p)}=p d_{(p)} / \operatorname{ipr}_{(p)}$

where $i p r_{(p)}=u p_{(p)}-l p_{(p)}$.

For non-symmetric distributions it is useful to look at the tails separately. Tail weight and upper and lower kurtosis coefficients can be evaluated for $0<p<0.25$. Tail length can be simply summarised by looking at $p=0.99$ (upper tail length, $u t l$ ) or $p=0.01$ (lower tail length, $l t l)$. For example, a distribution with $\left(u p_{(0.99)}-\right.$ med $) / 2 i p r>1$ is regarded as having a long right tail, if it is between 0 and 0.5 it is regarded short tailed $[5,8]$.

\subsection{Modelling within-ring wood density using the generalised lambda distribution}

We attempted to fit two normal distributions with five parameters to within-ring wood density using the maximum likelihood method [24]. The parameters were early-latewood zone separator (\%) and the first two moments for the two distributions $\left(\mu_{1}, \sigma_{1}, \mu_{2}, \sigma_{2}\right)$. The attempt was unsuccessful because the frequency distributions of the data were not normally distributed. A wide range of skewness and kurtosis coefficients can be modelled by the generalised form of Tukey's lambda distribution. Inverse of the cumulative distribution function has a simple closed form with four adjustable parameters. Sample quantiles $\left(Q_{(p)}\right)$ for wood density within each ring (zone) were modelled using the generalised lambda distribution [8]:

$$
Q_{(p)}=\lambda_{1}+\frac{p^{\lambda_{3}}-(1-p)^{\lambda_{4}}}{\lambda_{2}}
$$

where parameter $\lambda_{1}$ is related to the position of the distribution, $\lambda_{2}$ to its dispersion, and $\lambda_{3}$ and $\lambda_{4}$ to its shape and tail weight. The distribution was fitted to the within-ring micro-density data using the "nlm2" function of S-PLUS ${ }^{\circledR}$ package. The function estimates the parameters of a non linear regression model over a given set of observations, using Gauss-Marquardt algorithm [21].

\subsection{Analyses of variance and covariance}

All above mentioned distribution parameters provided within-ring information and were used to examine relationship between growth rate and within-ring wood density. Correlation analyses involving 
Table I. (a) Mean values (over three growing seasons) of quadratic and quantile based parameters and -function coefficients describing withinring distributions for Norway spruce (Ns), Douglas fir (Df), and maritime pine (Mp). (b) Correlations between growth rate expressed as ring width and parameters (and $\lambda$ function coefficients) describing within-ring wood density distributions. (Correlation coefficients with significance higher than $p=0.05$ are given in bold.)

\begin{tabular}{|c|c|c|c|c|c|c|c|c|c|c|c|c|c|c|c|c|c|c|c|}
\hline & & $\begin{array}{l}\text { Width } \\
(\mathbf{m m})\end{array}$ & $\%$ & Mean & $s d$ & $s k w$ & kur & $\min$ & med & $\max$ & $i q r$ & $q s k w$ & $q k u r$ & utl & lt $l$ & $\lambda_{1}$ & $\lambda_{2}$ & $\lambda_{3}$ & $\lambda_{4}$ \\
\hline \multicolumn{20}{|l|}{ (a) } \\
\hline Ns & I & 2.5 & 100 & 0.362 & 0.138 & 1.0 & 3.3 & 0.214 & 0.326 & 0.699 & 0.191 & 0.40 & 1.2 & 2.2 & 0.6 & 468 & 0.004 & 4.970 & 0.673 \\
\hline \multirow[t]{2}{*}{ Df } & EW & 3.2 & 61 & 0.270 & 0.072 & 1.3 & 3.8 & 0.197 & 0.242 & 0.475 & 0.086 & 0.60 & 1.5 & 2.8 & 0.6 & 345 & 0.008 & 6.185 & 0.577 \\
\hline & LW & 1.9 & 39 & 0.670 & 0.082 & -0.5 & 2.7 & 0.486 & 0.679 & 0.789 & 0.122 & -0.10 & 1.3 & 1.0 & 1.8 & 626 & 0.007 & 3.003 & 5.313 \\
\hline \multirow[t]{2}{*}{ Mp } & EW & 2.6 & 62 & 0.301 & 0.037 & 0.8 & 3.2 & 0.253 & 0.290 & 0.392 & 0.056 & 0.20 & 1.3 & 2.3 & 0.8 & 323 & 0.017 & 6.580 & 1.138 \\
\hline & LW & 1.7 & 38 & 0.514 & 0.055 & 0.2 & 2.6 & 0.411 & 0.511 & 0.626 & 0.078 & 0.00 & 1.3 & 1.6 & 1.3 & 522 & 0.010 & 4.766 & 2.846 \\
\hline \multicolumn{20}{|l|}{ (b) } \\
\hline $\mathbf{N s}^{1}$ & I & 1.00 & I & -0.79 & -0.16 & 0.79 & 0.76 & -0.72 & -0.79 & 0.08 & -0.54 & 0.44 & 0.57 & 0.76 & -0.06 & -0.27 & -0.47 & 0.71 & -0.72 \\
\hline \multirow[t]{2}{*}{$\mathrm{Dg}^{1}$} & EW & 0.96 & 0.39 & -0.33 & 0.51 & 0.22 & 0.24 & -0.51 & -0.38 & 0.26 & 0.34 & 0.09 & 0.09 & 0.33 & 0.25 & 0.02 & -0.59 & -0.08 & -0.26 \\
\hline & LW & 0.87 & -0.43 & 0.15 & -0.10 & 0.7 & -0.24 & 0.31 & 0.06 & 0.27 & -0.06 & 0.45 & 0.09 & 0.65 & -0.32 & 0.55 & 0.27 & 0.10 & 0.03 \\
\hline \multirow[t]{2}{*}{$\mathbf{M p}^{2}$} & EW & 0.84 & 0.34 & -0.25 & -0.05 & -0.42 & -0.41 & -0.30 & -0.25 & -0.27 & 0.13 & -0.16 & -0.10 & -0.29 & 0.03 & -0.38 & 0.20 & -0.06 & -0.03 \\
\hline & LW & 0.70 & -0.49 & -0.32 & -0.55 & 0.24 & -0.05 & -0.06 & -0.33 & -0.38 & -0.46 & 0.25 & -0.01 & 0.07 & -0.30 & -0.26 & 0.53 & 0.28 & -0.22 \\
\hline
\end{tabular}

1 Significant correlation coefficients: $r_{(\mathrm{df}=49, p=0.05)}=0.27$ and $r_{(\mathrm{df}=49, p=0.01)}=0.35$.

2 Significant correlation coefficients: $r_{(\mathrm{df}=42, p=0.05)}=0.30$ and $r_{(\mathrm{df}=42, p=0.01)}=0.39$.

those parameters and ring width (RW) were performed by S-PLUS ${ }^{\circledR}$ package [21]. Histograms illustrating change in within-ring density distributions associated with increased growth rate were also obtained from S-PLUS ${ }^{\circledR}$ package. The histograms were based on regression analyses of RW and lambda parameters for each of the three examined species.

Environmental and genetic (clone) control of the variability of distribution position and shape was examined through analyses of variance. Heritability for distribution parameters could not be calculated because the clones were not a random sample from their parent population. Nevertheless, statistical significance of clone differences indicates significant genetic differences.

Preliminary analyses of variance (ANOVA) including 20 common Ns clones grown on two sites in Sweden showed no significant clone by planting site interactions. Analyses including all $45 \mathrm{Ns}$ clones were done independently assuming clones being nested within two sites. Analyses for the other two species (Df and $\mathrm{Mp}$ ) included only one planting site.

Repeated measurement ANOVA was used to analyse clone variation over three growing seasons. The clone effect was in a factorial relationship with the growing season effects (calendar year or cambial age). Within tree errors were not independent, however, because adjacent rings tend to be more correlated than in rings several years apart. Formation of cambial initials always in the previous growing season provides a simple explanation for this correlation [4]. The covariance structure of errors was be modeled by using statement REPEATED in procedure MIXED of SAS/STAT ${ }^{\circledR}$, which provide different structures for within subject variance-covariance matrices $[19,20]$. The most appropriate one, with the property of correlation being larger for nearby rings than for those far apart, is auto-regressive of order 1 (AR1). This AR1 correction is important for the inferences about the main experimental effects. Alternatively, due to the large computer memory required to perform the above procedure, statement REPEATED in procedure GLM of SAS/STAT ${ }^{\circledR}$ was also used for the analysis $[19,20]$. This is equivalent to using the unstructured covariance for multivariate tests of main effects, or compound symmetry for adjusted univariate $F$ tests of time (within subject) effects [12].
Because of the assumption the conservative tests were used to test the significance of the within subject factors (i.e. year and clone by year interaction) [21, p. 434].

Clone variability for within-ring parameters was also examined after adjustments for ring width and mean ring density through analyses of covariance (ANCOVA). The procedure GLM of SAS/ STAT $^{\circledR}$ does not allow matching up of data columns for growing season and covariates (ring width or whole ring density). Data format used in procedure MIXED of SAS/STAT ${ }^{\circledR}$ allows this modelling using restricted maximum likelihood $[19,20]$. In that case, after homogeneity of slopes was tested for covariates within clones, two models were possible: equal slopes or nested slopes. The choice of model influenced the statistical significance of the main factor. The unequal regression coefficient model was tested [12]. In such a model, regression coefficients are assumed to be homogenous within groups and different between groups (i.e. clones). Such coefficients represent clone effects not explained by covariates. This analysis was used to assess the relative contribution of clone differences to the overall variation in shape of within-ring frequency distributions of wood density.

\section{RESULTS}

\subsection{Statistics describing within-ring distribution of wood density}

From wood density histograms within a single ring (Fig. 1) it was observable that in Norway spruce (Ns) the frequency distribution of wood density was more or less uni-modal and asymmetric (i.e. positively skewed). In Douglas fir (Df) and Maritime pine (Mp), the distribution was bimodal, a mixture of two skewed distributions corresponding to early- and latewood ring zones. Mean values over three growing seasons of quadratic and quantile based parameters and lambda coefficients describing within-ring distributions for clones of tree species are given in Table Ia. Df and Mp had approximately same proportion of latewood, little less than $40 \%$. The average 
Table II. Average values of goodness of fit statistics for the fitted distributions for each of three rings and within-ring zones for Norway spruce (Ns), Douglas fir (Df), and maritime pine (Mp).

\begin{tabular}{|c|c|c|c|c|c|c|c|}
\hline Species & Year & Zone $^{1}$ & $\chi^{2}$ & $d f$ & $p$ & $K-S D$ & $p$ \\
\hline \multirow{3}{*}{ Ns } & 1994 & WR & 20.6 & 18.9 & 0.31 & 0.10 & 0.77 \\
\hline & 1995 & WR & 21.4 & 19.5 & 0.32 & 0.07 & 0.88 \\
\hline & 1996 & WR & 19.4 & 18.5 & 0.37 & 0.09 & 0.87 \\
\hline \multirow{6}{*}{ Df } & 1995 & EW & 21.3 & 20.4 & 0.38 & 0.10 & 0.70 \\
\hline & & LW & 16.7 & 18.9 & 0.54 & 0.09 & 0.93 \\
\hline & 1996 & EW & 20.3 & 20.5 & 0.41 & 0.09 & 0.89 \\
\hline & & LW & 17.5 & 16.3 & 0.35 & 0.10 & 0.78 \\
\hline & 1997 & EW & 22.2 & 19.2 & 0.27 & 0.09 & 0.64 \\
\hline & & LW & 14.3 & 16.8 & 0.58 & 0.13 & 0.89 \\
\hline \multirow{6}{*}{ Mp } & 1997 & EW & 30.3 & 20.5 & 0.06 & 0.12 & 0.32 \\
\hline & & LW & 22.9 & 20.6 & 0.30 & 0.13 & 0.77 \\
\hline & 1998 & EW & 25.6 & 23.8 & 0.32 & 0.10 & 0.70 \\
\hline & & LW & 20.9 & 21.5 & 0.46 & 0.07 & 0.90 \\
\hline & 1999 & EW & 25.8 & 24.2 & 0.35 & 0.11 & 0.56 \\
\hline & & LW & 18.9 & 19.6 & 0.47 & 0.07 & 0.92 \\
\hline
\end{tabular}

${ }^{1} \mathrm{WR}=$ whole ring, EW = earlywood, LW = latewood.

wood density was 0.426 for $\mathrm{Df}, 0.385$ for $\mathrm{Mp}$ and 0.362 for $\mathrm{Sp}$. The whole-ring values of standard deviation were in magnitude order of 0.201 for Df, 0.138 for Ns and 0.106 for Mp, giving coefficients of variation of $47 \%, 38 \%$ and $28 \%$ respectively. Df had the coefficient of variation almost 1.7 times that of Mp. While the whole ring interquartile range (iqr) was also the highest for Df $(i q r=0.437)$, the species rankings reversed for $\mathrm{Mp}$ $(i q r=0.221)$ and Ns $(i q r=0.191)$, perhaps because the density values were more extreme for Ns. Moment-based estimates of skewness $(s k w)$ paralleled approximately the percentile-based $(q s k w)$ estimates. There were generally low values for momentbased kurtosis (kur) and quantile based (qkur) parameters (e.g. values of kur lower than 3 and values of $q k u r$ lower than 1 imply a peaked distribution). The upper tail length ( $u t l)$ was especially high in Ns and earlywood of Df and Mp.

\subsection{Modelling within-ring wood density using the generalised lambda distribution}

Observed and expected distributions were first compared visually using Quantile-Quantile (Q-Q) plots (Fig. 2). Pearson's Chi-squared Test $\left(\chi^{2}\right)$ and Kolmogorov-Smirnov (K-S) goodness of fit tests were used to statistically test the identity of modeled distributions. For the $\chi^{2}$ test data were grouped so that the number of observations per interval was $\geq 5$ and number of intervals $\approx 20$. When modelled using the generalised lambda distribution, more than $95 \%$ of sampled rings in all tree species had a $\chi^{2}$ goodness of fit measure smaller than appropriate value $\chi^{2}(p=0.05)$. For Ns and Df, the $\chi^{2}$ values were in more than $80 \%$ of distributions smaller than the $\chi^{2}(p=0.25)$. Similar nonsignificant results were obtained by using the exact $p$-values of K-S for two-sided test (Tab. II). The non-significant tests indicated that overall good fit can be obtained by using the four

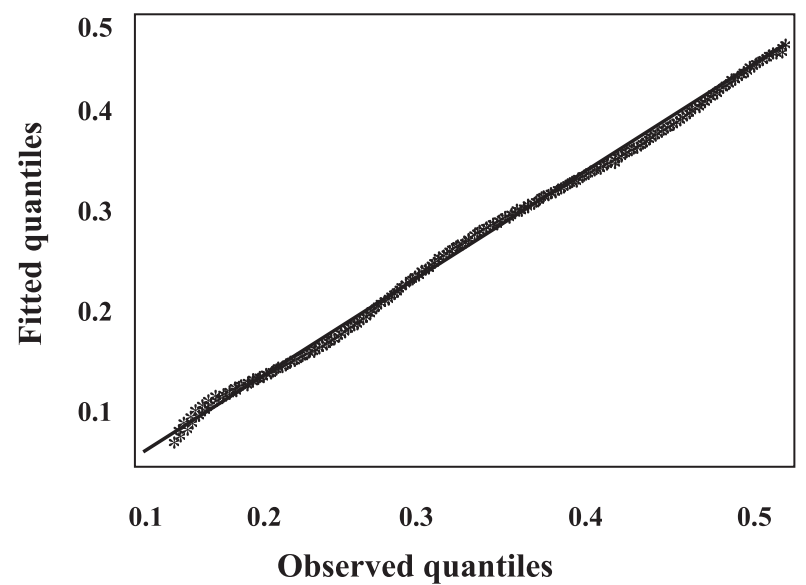

Figure 2. Q-Q plot of fitted earlywood density distribution for profile Df: 11-1995.

parameter function. The residual values resulting from the function were unbiased when compared with predicted values. Exception was the ring 1997 of Mp containing unusually high density peaks in EW (i.e. false rings) for which was difficult to obtain a good fit (Tab. II).

Values of the estimated lambda coefficients $\lambda_{1}$ and $\lambda_{2}$ for individual rings generally paralleled in magnitude the values of moment based statistics: $\lambda_{1}$ followed values of mean and $\lambda_{2}$ followed (inversely) values of standard deviation. The only exception was the ring 1997 of maritime pine containing an unusually high density peak (i.e. false ring), which was difficult to model (Tab. Ia). 


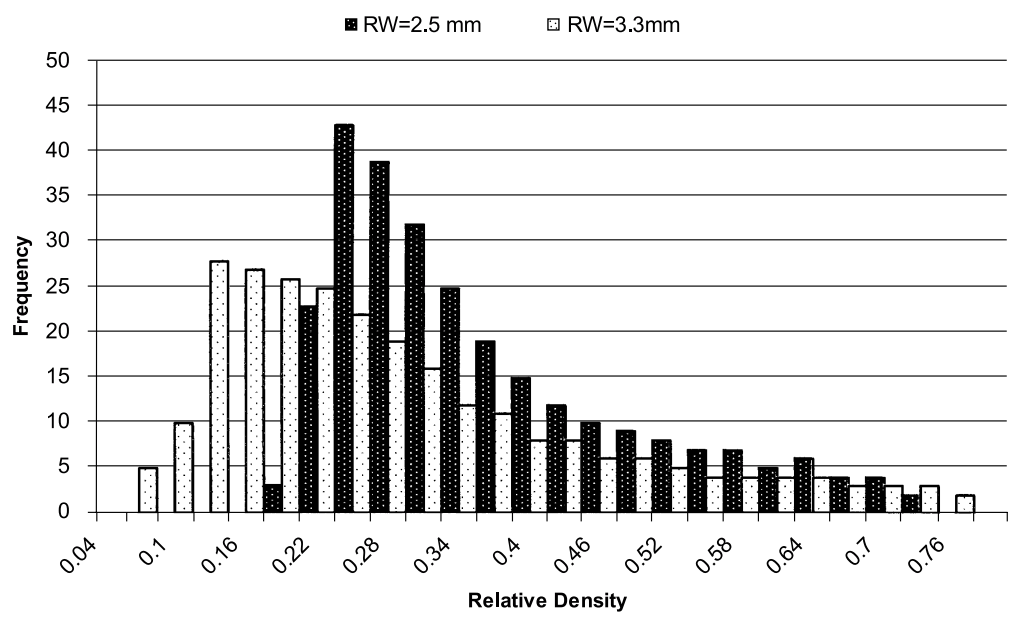

Figure 3. Expected change in the position and shape of within-ring density distribution after one $s d$ increase in growth ring width (RW) relative to average distribution for Norway spruce (Ns).

\subsection{Correlation between growth rate and within-ring density}

Df had the highest mean wood relative density (0.426) and the fastest growth rate expressed as ring width $(5.1 \mathrm{~mm}) . \mathrm{Mp}$ had intermediate wood density $(0.382)$ and intermediate ring width $(4.3 \mathrm{~mm})$. Ns had the lowest density (0.362) and slowest growth $(2.5 \mathrm{~mm})$. In spite of these among species comparisons, within individual species growth rate (expressed as ring width) was negatively correlated with wood density (Tab. Ib). In Table Ib is shown that certain number of moment and quantile based distribution parameters had significant correlations with ring width. In some cases, those correlations were higher than the correlation between ring width and mean ring density: In Ns, ring width had strong correlations $(r>|0.5|, p<0.01)$ with most position (mean, $q_{0}-q_{3}$ ), dispersion (iqr) and shape parameters (skw, kur, qkur, utl) of frequency distribution. For Df and $\mathrm{Mp}$, ring width had strong correlations with the width of the EW and LW zones and weaker but significant correlations with zone proportions (i.e. increasing ring width increased $\mathrm{EW}$ and decreased LW proportion). The correlations were weak or non significant for most within zone position, dispersion, or shape parameters (e.g. correlation of ring width with mean, med, kur or $q k u r)$. Some $\lambda$ function coefficients were also more closely correlated with growth rate than parameters describing withinring wood density (e.g. correlation of RW with $\lambda_{2}$ in Sp, Df and in $\mathrm{LW}$ of $\mathrm{Mp}$ was higher than correlation of RW with $s d$ ). For Ns, significant regression coefficients $(p<0.05)$ were obtained between RW and four estimated $\lambda$ parameters. They were used to graphically represent expected changes in the position and shape of within-ring density distribution in Sp. The expected change in distribution of within-ring density for one $s d$ increase in ring width is presented in Figure 3.

\subsection{Differences among clones in within-ring density}

Fluctuations in growth rate and within-ring density distributions are related to the confounded effects of climate within each growing season and cambial age of growth rings. Annual incre- ments can also show presence of genotype $(\mathrm{Cl})$ by growing season $(\mathrm{Y})$ interaction with possible rank changes among clones. Differences among clones and clone by growing season interactions $(\mathrm{Cl} \times \mathrm{Y})$ were analyzed through repeated measures analyses of variance (ANOVA). The results are presented in Table III. Although, Y effect was significant $(p=0.001)$ for width and mean relative density of rings in all three species, this effect was not the main interest of the study. More interestingly, $\mathrm{Cl}$ effect was significant in all three species for width, mean, quantile location parameters including median and coefficient $\lambda_{1}$. For distribution quantiles, the range of variation in clone means was the highest for Df, especially in the LW (Fig. 4). In general, significance of $\mathrm{Cl}$ effect was similar for moment $(s d)$ and quantile (iqr) based dispersion parameters and for lambda function dispersion coefficient $\left(\lambda_{2}\right)$. Significance of $\mathrm{Cl}$ effect was also similar for moment (skw, kur) and quantile based ( $q s k w, q k u r)$ shape parameters, and lambda function coefficients $\left(\lambda_{3}\right.$ and $\left.\lambda_{4}\right) . \mathrm{Cl} \times \mathrm{Y}$ interaction was significant for ring and zone width, and for wood density distribution position parameters. It was of less significance for dispersion and shape of the distributions in Df and Mp. For the most part, quantile based and $\lambda$ function coefficients had similar significance of $\mathrm{Cl}$ and $\mathrm{Cl} \times \mathrm{Y}$ variation as moment based parameters.

Analysis of covariance (ANCOVA) was performed on all types of parameters using first growth rate expressed as ring width (RW) and then mean ring density (RD) as covariates to examine causes of variability in the position and shape of distribution of wood density. (Ring area was not used because of its non-linear relationship with mean ring density). The results of ANCOVA using RW as the covariate are presented in Table IV. RW was a significant covariate for most parameters in Ns and for width and proportion of latewood \% in Df and Mp. However, RW was not a significant covariate for mean density (and most other distribution position parameters) of LW zone in Df and Mp. Cl effect for width and \% had no significance after the adjustment in Mp but stayed significant in Df. In all three species, analyses of covariance revealed that, after adjustment for ring width, there were still highly significant 
Table III. Analyses of variance ( $F$ values and associated probability $\left.{ }^{1}\right)$ including moment and quantile based parameters and $\lambda$-function coefficients describing within-ring distribution of wood density in Norway spruce (Ns), Douglas fir (Df) and maritime pine (Mp). Sources of variation are: clone $(\mathrm{Cl})$, year $(\mathrm{Y})$ and clone by year interaction $(\mathrm{Cl} \times \mathrm{Y})$.

\begin{tabular}{|c|c|c|c|c|c|c|c|c|c|c|c|c|c|c|c|c|c|c|c|c|}
\hline Sp. & Source & $\frac{\mathrm{NDF}}{\mathrm{DDF}}$ & Width & $\%$ & Mean & $s d$ & $s k w$ & kur & $\min$ & med & $\max$ & $i q r$ & $q s k w$ & $q k u r$ & utl & ltl & $\lambda_{1}$ & $\lambda_{2}$ & $\lambda_{3}$ & $\lambda_{4}$ \\
\hline \multirow{4}{*}{ Ns } & \multirow{2}{*}{$\mathrm{Cl}$} & 44 & 2.91 & 1 & 3.50 & 2.74 & 2.83 & 2.15 & 3.74 & 3.85 & 2.16 & 2.90 & 1.59 & 2.83 & 2.40 & 2.90 & 2.34 & 1.98 & 2.12 & 2.24 \\
\hline & & 252 & 0.000 & I & 0.000 & 0.007 & 0.000 & 0.000 & 0.000 & 0.000 & 0.008 & 0.000 & 0.000 & 0.000 & 0.000 & 0.000 & 0.000 & 0.008 & 0.000 & 0.000 \\
\hline & \multirow{2}{*}{$\mathrm{Cl} \times \mathrm{Y}$} & 88 & 2.84 & I & 2.41 & 1.95 & 2.29 & 2.05 & 2.05 & 2.10 & 2.18 & 2.23 & 1.09 & 2.21 & 2.08 & 1.49 & 2.61 & 1.73 & 2.07 & 1.32 \\
\hline & & 426 & 0.000 & I & 0.000 & 0.001 & 0.000 & 0.000 & 0.000 & 0.000 & 0.000 & 0.000 & 0.274 & 0.000 & 0.000 & 0.027 & 0.000 & 0.000 & 0.000 & 0.094 \\
\hline \multirow[t]{3}{*}{ Df } & \multirow{2}{*}{$\mathrm{Cl}$} & 49 & 5.07 & I & 51 & 1.76 & 1.15 & 1.40 & 2.94 & 2.68 & 1.97 & 1.45 & 1.43 & 1.17 & 1.41 & 0.81 & 2.09 & 1.88 & 1.92 & 0.95 \\
\hline & & 112 & 0.000 & I & 0.000 & 0.008 & 0.269 & 0.076 & 0.000 & 0.000 & 0.002 & 0.056 & 0.064 & 0.245 & 0.072 & 0.793 & 0.001 & 0.003 & 0.003 & 0.566 \\
\hline & \multirow{2}{*}{$\mathrm{Cl} \times \mathrm{Y}$} & 98 & 1.86 & I & 1.69 & 1.53 & 1.63 & 1.67 & 1.55 & 1.50 & 1.82 & 1.44 & 1.13 & 1.36 & 1.54 & 1.04 & 1.68 & 1.53 & 2.02 & 1.11 \\
\hline EW & & 276 & 0.000 & I & 0.014 & 0.038 & 0.021 & 0.017 & 0.027 & 0.046 & 0.006 & 0.015 & 0.236 & 0.100 & 0.036 & 0.424 & 0.015 & 0.038 & 0.002 & $\mathbf{0 . 3 3 1}$ \\
\hline \multirow{4}{*}{ LW } & \multirow{2}{*}{$\mathrm{Cl}$} & 49 & 2.88 & 4.06 & 3.700 & 1.110 & 2.020 & 1.400 & 1.490 & 4.000 & 4.190 & 1.130 & 1.190 & 0.970 & 3.900 & 1.080 & 2.500 & 1.490 & 0.710 & 1.140 \\
\hline & & 112 & 0.000 & 0.000 & 0.000 & 0.321 & 0.001 & 0.075 & 0.044 & 0.000 & 0.000 & 0.293 & 0.230 & 0.544 & 0.000 & 0.360 & 0.000 & 0.046 & 0.909 & 0.286 \\
\hline & \multirow{2}{*}{$\mathrm{Cl} \times \mathrm{Y}$} & 98 & 0.09 & 1.10 & 0 & 1.19 & 0 & 9 & F) & 1.62 & 1.44 & 1.22 & 1.44 & 1.02 & 4 & 0.91 & 1.80 & 1.24 & 0.80 & 1.39 \\
\hline & & 276 & 0.060 & 0.338 & 0.001 & 0.150 & 0.185 & 0.145 & 0.009 & 0.002 & 0.014 & 0.118 & 0.014 & 0.451 & 0.000 & 0.692 & 0.000 & 0.098 & 0.901 & 0.024 \\
\hline \multirow[t]{3}{*}{$\overline{M p}$} & \multirow{2}{*}{$\mathrm{Cl}$} & 41 & 1.83 & 1 & 5.28 & 1.04 & 1.46 & 1.45 & 6.36 & 5.01 & 3.03 & 0.91 & 1.03 & 1.70 & 2.15 & 1.29 & 4.28 & 1.11 & 0.85 & 0.93 \\
\hline & & 149 & 0.005 & I & 0.000 & 0.426 & 0.059 & 0.062 & 0.000 & 0.000 & 0.000 & 0.627 & 0.446 & 0.014 & 0.001 & 0.143 & 0.000 & 0.324 & 0.718 & 0.593 \\
\hline & \multirow{2}{*}{$\mathrm{Cl} \times \mathrm{Y}$} & 82 & 1.95 & I & 1.46 & 1.26 & 1.29 & 1.29 & 1.72 & 1.41 & 1.45 & 1.15 & 1.06 & 1.14 & 1.32 & 0.85 & 1.58 & 1.06 & 1.02 & 0.92 \\
\hline EW & & 261 & 0.000 & I & 0.014 & 0.092 & 0.073 & 0.070 & 0.001 & 0.024 & 0.016 & 0.210 & 0.371 & 0.215 & 0.053 & 0.805 & 0.004 & 0.354 & 0.443 & 0.663 \\
\hline \multirow{4}{*}{ LW } & \multirow{2}{*}{$\mathrm{Cl}$} & 41 & 1.69 & 1.45 & 3.82 & 2.09 & 1.01 & 1.74 & 1.88 & 3.32 & 4.91 & 1.64 & 1.53 & 1.33 & 0.97 & 2.37 & 4.55 & 2.13 & 1.23 & 1.56 \\
\hline & & 149 & 0.017 & 0.063 & 0.000 & 0.001 & 0.469 & 0.011 & 0.005 & 0.000 & 0.000 & 0.021 & 0.039 & 0.119 & 0.534 & 0.000 & 0.000 & 0.001 & 0.198 & $\mathbf{0 . 0 3 5}$ \\
\hline & \multirow[t]{2}{*}{$\mathrm{Cl} \times \mathrm{Y}$} & 82 & 1.42 & 1.35 & 1.62 & 1.14 & 0.98 & 1.57 & 1.37 & 1.48 & 1.80 & 1.23 & 1.17 & 1.12 & 1.05 & 0.89 & 1.54 & 1.24 & 1.48 & 0.83 \\
\hline & & 261 & 0.022 & 0.044 & 0.003 & 0.226 & 0.537 & 0.004 & 0.035 & 0.012 & 0.000 & 0.114 & 0.183 & 0.256 & 0.387 & 0.731 & 0.007 & 0.108 & 0.012 & 0.836 \\
\hline
\end{tabular}

${ }^{1}$ Significance of $F$ values with $p<0.05$ is given in bold.

$(p<0.01)$ clonal variability in mean density (and other position parameters). In general the adjustment for $\mathrm{RW}$ influenced $\mathrm{Cl}$ and $\mathrm{CL} \times \mathrm{Y}$ significance for dispersion and shape parameters but to a lesser extent (Tab. IV).

Although, after adjusting for mean ring density, there was generally reduction in $\mathrm{F}$ values of $\mathrm{Cl}$ and $\mathrm{Cl} \times \mathrm{Y}$ effects for distribution position parameters (Tab. V), their significance still stayed high (except for $\mathrm{Cl}$ effect in EW of Df). There were no clear effects of the adjustment on dispersion and shape parameters. This means that clones with similar mean density had significantly different within-ring structure. None of the effects were significant after adjustment for both RW and RD at the same time. That could be of real biological significance or a result of the complexity of statistical model (Tab. V).

\section{DISCUSSION AND CONCLUSIONS}

Transition from earlywood to latewood is gradual in Norway spruce, while the transition is more or less abrupt in Douglas fir and Maritime pine. However, there is no universally accepted criterion for separation of early- and latewood zones. The criterion to separate those two classes is usually defined as the point in the ring where density equals the mean between minimum and maximum density values ("Average of Extremes
Method") or as a fixed value of density ("Threshold Method") $[14,23]$. If the boundary is defined by the Average of Extremes Method, the extreme size of a single wood density record (a single cell or a small number of wood cells) could cause a shift of the boundary. This shift of the boundary may occur although there might not have been a significant change if a fixed threshold was used. This consideration is more important for species with a gradual transition between early- and latewood such as spruces. Therefore we avoided such a separation in our analyses of Norway spruce, which had a unimodal distribution of withinring density. In Douglas fir and maritime pine, the distribution was bimodal (i.e. mixture of two distributions) with corresponding separation to early- and latewood ring zones.

Early-latewood separation does not give a clear description of the shape of whithin-ring density distribution. Because the within-ring density distributions are generally skewed, standard descriptive statistics may not be adequate [17]. In this paper we used multiple density classes based on the frequency distribution of within-ring (and within-zone) wood density. We reexamined the use of "classical" (moment-based) statistical parameters that describe within ring distribution of wood density. According to both moment based and quantile statistical parameters Df had the most variable within-ring density. The variability was intermediate for Ns while, despite common density 

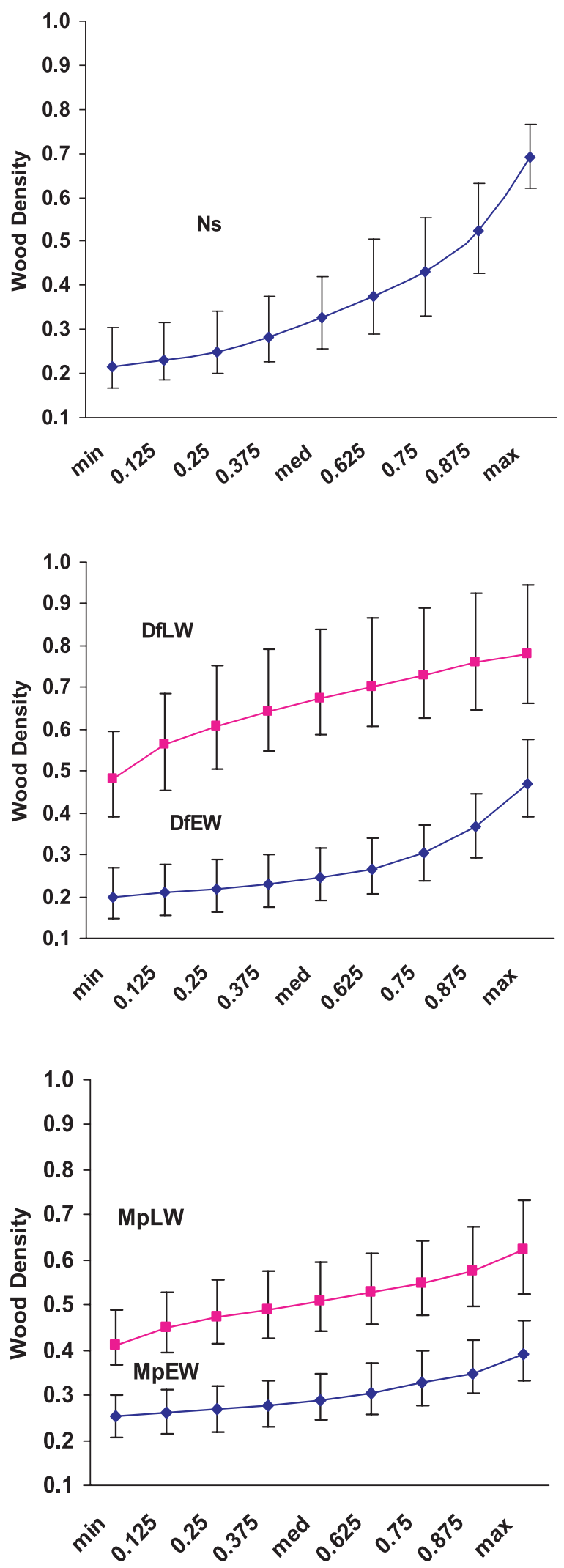

Figure 4. Overall means and ranges of variation in clone means (for three growing seasons) of distribution quantiles for Norway spruce (Ns), Douglas fir (Df) and Maritime pine (Mp). peaks in density profiles it was the lowest for Mp. Increase in growth rate was generally followed by change in range (decrease in $\mathrm{min}$ ), but not necessarily in general variability of wood density, except in EW of Df were the variability generally increased and in LW of Mp were the variability decreased.

Most of the models of within-ring wood density have been based on the time sequence of wood production or density profile (e.g. [16]). We disregarded the within-ring time sequence to obtain empirical frequency class distribution from within-ring density measurements. We used the generalised $\lambda$ distribution for modelling of within-ring frequency of wood density. Generally, modelling follows the principle of parsimony, but sometimes it is desirable to have more parameters, with each parameter controlling a different aspect $[5,8]$. The aspects described by generalised distribution are position, dispersion and shape (i.e. left and right skew, kurtosis and tail length). The fit for within ring wood density was generally good. Nonetheless it was more difficult to model within-ring density in Maritime pine rings because of plateaus and multiple peaks (false rings) in density profiles.

Norway spruce, Douglas fir and Maritime pine have generally negative correlation between mean wood density and radial growth rate [30]. The negative correlation is typically the most pronounced in Ns. When various within-ring moment and quantile based statistical parameters were used to correlate with growth rate the correlation coefficients varied. In some cases, those correlations were higher than the correlation between ring width and mean ring density. The relationship between growth and density is based on underlying physiological processes, which could be understood better, by considering a variety of basic and composite traits $[11,25,26]$. There is evidence of anatomical differences among trees of same wood density [6]. It is important to determine whether such differences have a genetic basis. It is also important to determine how selection for growth and mean wood density affects density components and how the change in these component traits is related to the value of final products.

Mean ring density as a composite trait and its components such as latewood percentage, earlywood and latewood density are all under certain genetic control [27-29]. We show that some other component traits (i.e. moment and quantile based statistics and $\lambda$-function coefficients) had also substantial genetic variation and can potentially be useful for circumventing the negative correlation of growth rate with wood density through clone selection and deployment. For coefficients related to position of density distribution differences among clones and clone by growing season interactions were significant in all three species. For coefficients related to dispersion and shape of density distribution significance of clone and clone by growing season interactions effect was varied. The high significance in some cases may be a consequence of the fact that clones are not necessarily a random selection from the population.

In this study, ring width and ring density were examined as covariates or "mechanism variables" [12] in the causal path between the treatment $(\mathrm{Cl}, \mathrm{Cl} \times \mathrm{Y})$ and the examined response variables. In all three species, analyses of covariance revealed that, after adjustment for ring width, there were still significant clonal variability in mean ring density and certain within-ring frequency distribution parameters. Even after adjusting for 
Table IV. Analyses of covariance ( $F$ values and associated probability $\left.{ }^{1}\right)$ including moment and quantile based parameters and $\lambda$-function coefficients describing within-ring distribution of wood density. Sources of variation are: ring width (RW), clone $(\mathrm{Cl})$, year $(\mathrm{Y})$ and clone by year interaction $(\mathrm{Cl} \times \mathrm{Y})$.

\begin{tabular}{|c|c|c|c|c|c|c|c|c|c|c|c|c|c|c|c|c|c|c|c|c|}
\hline p. & & $\frac{\mathrm{NDT}}{\mathrm{DDF}}$ & dth & $\%$ & in & sd & $w$ & $u r$ & in & ied & $\operatorname{ax}$ & $i q r$ & $k w$ & kur & utl & lt & $\lambda_{1}$ & $\lambda_{2}$ & $\lambda_{3}$ & $\lambda_{4}$ \\
\hline & & \multirow{2}{*}{426} & & t & & & & & & & & & & & & & & & & \\
\hline & & & I & I & & 0 & & 0 & & & 30 & 00 & b0 & & & 64 & 07 & 00 & 00 & .000 \\
\hline & & \multirow{2}{*}{$44 / 252$} & 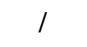 & I & & & & & & & & & & & & & & & & 30 \\
\hline & & & I & I & 000 & 0.000 & 0.000 & 0.002 & 0.000 & 0.000 & 0.000 & 0.000 & 0.002 & 0.000 & 0.000 & 0.000 & 0.000 & 0.005 & 0.055 & 0.00 \\
\hline & & \multirow{2}{*}{8} & 1 & 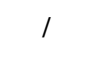 & & & & & & & & & & & & & & & & 1.33 \\
\hline & & & I & I & 000 & 0.000 & 0.000 & 0.000 & 0.000 & 0.000 & 0.000 & 0.000 & 0.275 & 0.000 & 0.000 & 0.011 & 0.000 & 0.000 & 0.000 & 0.026 \\
\hline \multirow[b]{2}{*}{$\mathbf{U}$} & & \multirow[b]{2}{*}{276} & & r & & & & & & & & & & & & & & & & 1 \\
\hline & & & 0.00 & I & 000 & 0.000 & 0.542 & 0.423 & 0.000 & 0.000 & 0.382 & 0.003 & 0.928 & 0.042 & 0.056 & 0.047 & 0.073 & 0.000 & 0.958 & 0.105 \\
\hline & & \multirow[b]{2}{*}{$49 / 112$} & & 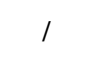 & & 4 & & & & & & & & & & & & & & 0.90 \\
\hline & & & 0.008 & I & 0.000 & 0.061 & 0.272 & 0.076 & 0.000 & 0.000 & 0.001 & 0.141 & 0.065 & 0.372 & 0.119 & 0.855 & 0.000 & 0.058 & 0.003 & 0.65 \\
\hline & & \multirow{2}{*}{ 98/276 } & & I & & & & & & & & & & & & 1.02 & 1.10 & & 2.01 & 11 \\
\hline & & & 0.191 & I & 0.000 & 0.008 & 0.002 & 0.001 & 0.000 & 0.001 & 0.000 & 0.024 & 0.230 & 0.032 & 0.006 & 0.441 & 0.001 & 0.006 & 0.000 & 0.257 \\
\hline & & \multirow[b]{2}{*}{76} & & & & & & & & & & & & & & & & & & 2.69 \\
\hline & & & 0.000 & 0.000 & 0.945 & 0.730 & 0.000 & 0.000 & 0.369 & 0.177 & 0.003 & 0.221 & 0.000 & 0.309 & 0.000 & 0.000 & 0.000 & 0.008 & 0.087 & 0.104 \\
\hline & & & & & & & & & & & & & & & & & & & & 12 \\
\hline & & 2 & 0. & 0. & 0 & 0 & 0 & 0. & & 0 . & o & 0 & 0 & & 0 & & 3 & 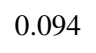 & & 0.17 \\
\hline & & \multirow{2}{*}{$98 / 276$} & 1.09 & & & & & & & 1 & 1 & & 1 & & 1.82 & 6 & 1.15 & 1.22 & 0.80 & 1.29 \\
\hline & & & 0.293 & 0 & 0 & 4 & 0 & 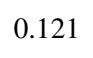 & c & 1 & $\mathbf{0}$ & 1 & 7 & & 0 & 76 & 0 & 3 & 9 & 06 \\
\hline & & \multirow{2}{*}{276} & & 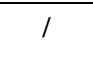 & & & & & & & & & & & & & & & & 1.23 \\
\hline & & & 0.0 & I & & 0.121 & & 0.000 & 0.000 & 0.018 & 0.616 & 0.008 & 0.235 & & & & & 0.376 & & 0.26 \\
\hline & & & & 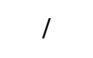 & & & & & & & & & & & & & & & & 0 \\
\hline E & & & 0.409 & I & 00 & 0.204 & 0.1 & 0. & 0 & 0.000 & $\mathbf{0}$ & 0.4 & 55 & & 1 & 0. & 00 & 01 & 18 & 0.50 \\
\hline & & & 1. & 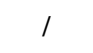 & & 6 & & 7 & & 24 & 13 & 4 & 55 & & 32 & 6 & 53 & 7 & 8 & 0.91 \\
\hline & & & o & I & 0 & 2 & 0. & 0 & 0 & 8 & $\mathbf{0}$ & 0.220 & 66 & & 7 & & 0.007 & 1 & & 0.67 \\
\hline & & & & & & & & & & & & & & & & & & & & 0.17 \\
\hline & & $1 / 276$ & & & & & & & & & & & & & & & & & & 0.02 \\
\hline & & & 1.28 & & & & 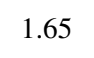 & 1.73 & 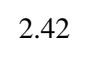 & 0 & 5.17 & . & 0 & 1. & 1.66 & 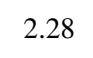 & . & 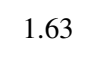 & 1 & 1.48 \\
\hline & & & 0.149 & 0.047 & 0.000 & 0.028 & 0.020 & 0.012 & 0.000 & 0.000 & 0.000 & 0.096 & 0.484 & 0.122 & 0.019 & 0.000 & 0.000 & 0.023 & 0.256 & 0.05 \\
\hline & & & & & & 1.14 & & & 1.37 & 1.64 & 1.48 & 1.2 & 1.08 & 1.12 & 1.72 & 0.89 & 1. & 1.24 & 1.48 & 0.83 \\
\hline & & & 0.003 & 0.044 & 0.003 & 0.226 & 0.001 & 0.004 & 0.035 & 0.002 & 0.012 & 0.114 & 0.319 & 0.256 & 0.001 & 0.731 & 0.007 & 0.108 & 0.012 & 0.83 \\
\hline
\end{tabular}

\footnotetext{
${ }^{1}$ Significance of $F$ values with $p<0.05$ is given in bold.
}

mean ring density there was still significant clonal variability in some statistical parameters describing within-ring frequency distribution of density classes (i.e. clones with similar mean density had different within-ring structure). In most cases quantile based and function coefficients had similar significance of $\mathrm{Cl}$ and $\mathrm{Cl} \times \mathrm{Y}$ variation as moment based parameters. More complex models imply that covariates have different effects for each clone. This led to the conclusion that exist not only clones with fast growth and high mean wood density, but also ones with favourable internal structure (e.g. more uniform withinring structure or higher proportion of certain type of wood within a ring).
The within-ring variation is the most significant source of wood variation, and wood uniformity is one of the main requirements by the processing industry [30]. That underlines the importance of modelling within-ring wood variation as a tool used for evaluating wood resource quality. Highly significant clone differences and strong correlations with growth and potentially some processing parameters and end-product quality $[7,9]$ imply a potential utility of within-ring parameters for clonal selection for breeding and deployment [17]. Besides providing the additional information about within-ring structure, an advantage of the frequency distribution over density profile presentation is that the internal structure can be described and 
Table V. Analyses of covariance ( $F$ values and associated probability ${ }^{1}$ ) including moment and quantile based parameters and $\lambda$ function coefficients describing within-ring distribution of wood density. Sources of variation are: ring density (RD), clone $(\mathrm{Cl})$, year $(\mathrm{Y})$ and clone by year interaction $(\mathrm{Cl} \times \mathrm{Y})$.

\begin{tabular}{|c|c|c|c|c|c|c|c|c|c|c|c|c|c|c|c|c|c|c|c|c|}
\hline Sp. & Source & $\frac{\mathrm{NDF}}{\mathrm{DDF}}$ & Width & $\%$ & Mean & $s d$ & $s k w$ & kur & $\min$ & med & $\max$ & $i q r$ & $q s k w$ & $q k u r$ & utl & ltl & $\lambda_{1}$ & $\lambda_{2}$ & $\lambda_{3}$ & $\lambda_{4}$ \\
\hline \multirow{6}{*}{ Ns } & \multirow{2}{*}{ RD } & \multirow{2}{*}{$1 / 426$} & 4 & I & I & 53.4 & 36 & 4 & 90 & 4766 & 39.2 & 282 & 1 & .3 & 321.3 & 0.69 & 149 & 1.9 & 205 & 261 \\
\hline & & & 0.000 & I & I & 0.000 & 0.000 & 0.000 & 0.000 & 0.000 & 0.000 & 0.000 & 0.000 & 0.000 & 0.000 & 0.408 & 0.000 & 0.001 & 0.000 & 0.000 \\
\hline & \multirow{2}{*}{$\mathrm{Cl}$} & \multirow{2}{*}{$44 / 252$} & 2.35 & I & I & 3.08 & 18 & 1.88 & 3.65 & 2.26 & 1.87 & 3.93 & 1.49 & 2.76 & 2.35 & 3.04 & 1.73 & 1.84 & 1.74 & 1.16 \\
\hline & & & 0.000 & I & I & 0.000 & 0.000 & 0.001 & 0.000 & 0.000 & 0.001 & 0.000 & 0.027 & 0.000 & 0.000 & 0.000 & 0.004 & 0.001 & 0.004 & 0.233 \\
\hline & \multirow{2}{*}{$\mathrm{Cl} \times \mathrm{Y}$} & \multirow{2}{*}{$88 / 426$} & 2.61 & I & I & 1.57 & 2.68 & 2.22 & 1.85 & 1.72 & 1.81 & 1.90 & 1.13 & 2.15 & 2.15 & 1.59 & 2.28 & 1.58 & 2.10 & 1.19 \\
\hline & & & 0.000 & I & I & 0.001 & 0.000 & 0.000 & 0.000 & 0.000 & 0.000 & 0.000 & 0.200 & 0.000 & 0.000 & 0.001 & 0.000 & 0.001 & 0.000 & 0.121 \\
\hline \multirow{2}{*}{ Df } & \multirow{2}{*}{ RD } & \multirow{2}{*}{$1 / 276$} & 84.5 & I & 274 & 0.14 & 03 & .88 & 326 & 296 & 52.1 & 2.15 & 1.09 & 11.1 & 13.7 & 0.32 & 113 & 1.67 & 1.00 & 13 \\
\hline & & & 0.000 & I & 0.000 & 0.707 & 0.003 & 0.006 & 0.000 & 0.000 & 0.000 & 0.145 & 0.298 & 0.001 & 0.000 & 0.570 & 0.000 & 0.199 & 0.320 & 0.000 \\
\hline \multirow{6}{*}{ EW } & \multirow{2}{*}{$\mathrm{Cl}$} & \multirow{2}{*}{$49 / 112$} & 5.36 & I & 1.21 & 1.76 & 1.10 & 1.32 & 1.68 & 1.43 & 1.70 & 1.48 & 1.41 & 1.21 & 1.39 & 0.80 & 1.33 & 1.88 & 1.98 & 0.85 \\
\hline & & & 0.000 & I & 0.202 & 0.008 & 0.331 & 0.115 & 0.013 & 0.064 & 0.012 & 0.046 & 0.073 & 0.202 & 0.082 & 0.813 & 0.109 & 0.003 & 0.002 & 0.737 \\
\hline & \multirow{2}{*}{$\mathrm{Cl} \times \mathrm{Y}$} & \multirow{2}{*}{ 98/276 } & 2.24 & I & 1.49 & 1.57 & 1.65 & 1.64 & 1.52 & 1.43 & 1.75 & 1.42 & 1.08 & 1.43 & 1.55 & 1.09 & 1.53 & 1.59 & 2.07 & 1.26 \\
\hline & & & 0.000 & I & 0.008 & 0.003 & 0.001 & 0.001 & 0.006 & 0.016 & 0.000 & 0.017 & 0.321 & 0.016 & 0.004 & 0.296 & 0.005 & 0.003 & 0.000 & 0.082 \\
\hline & & & 0.01 & 25.4 & 190.2 & 13.6 & 15.1 & 2.69 & 29.9 & 225.5 & 180.7 & 4.86 & 6.53 & 0.37 & 16.2 & 3.20 & 37.8 & 30.2 & 2.77 & 0. \\
\hline & 10 & & 0.939 & 0.000 & 0.000 & 0.000 & 0.000 & 0.104 & 0.000 & 0.000 & 0.000 & $\mathbf{0 . 0 3 0}$ & 0.012 & 0.544 & 0.000 & 0.076 & 0.000 & 0.000 & 0.099 & 0.687 \\
\hline \multirow{4}{*}{ LW } & \multirow{2}{*}{$\mathrm{Cl}$} & \multirow{2}{*}{$49 / 112$} & 3.17 & 2.24 & 3.17 & 0.86 & 1.80 & 1.37 & 1.42 & 3.10 & 3.69 & 1.03 & 1.10 & 0.95 & 3.75 & 1.02 & 2.64 & 1.00 & 0.69 & 1.16 \\
\hline & & & 0.000 & 0.000 & 0.000 & 0.712 & 0.006 & 0.089 & 0.068 & 0.000 & 0.000 & 0.434 & 0.331 & 0.570 & 0.000 & 0.461 & 0.000 & 0.493 & 0.928 & 0.258 \\
\hline & \multirow{2}{*}{$\mathrm{Cl} \times \mathrm{Y}$} & \multirow{2}{*}{$98 / 276$} & 0.979 & 1.28 & 1.50 & 1.16 & 1.17 & 1.30 & 1.45 & 1.45 & 1.37 & 1.16 & 1.50 & 1.14 & 1.89 & 1.02 & 1.73 & 1.26 & 0.79 & 1.37 \\
\hline & & & 0.541 & 0.159 & 0.008 & 0.191 & 0.170 & 0.056 & 0.013 & 0.012 & 0.028 & 0.180 & 0.008 & 0.210 & 0.000 & 0.447 & 0.001 & 0.080 & 0.905 & 0.031 \\
\hline \multirow{2}{*}{ Mp } & \multirow{2}{*}{ RD } & \multirow{2}{*}{$1 / 276$} & 455.9 & I & 170.2 & 1.88 & 2.72 & 5.12 & 454 & 175 & 44.4 & 3.34 & 0.09 & 4.92 & 2.09 & 0.57 & 124.1 & 0.09 & 0.40 & 1.18 \\
\hline & & & 0.000 & I & 0.000 & 0.173 & 0.102 & 0.026 & 0.000 & 0.000 & 0.000 & 0.070 & 0.761 & 0.029 & 0.151 & 0.451 & 0.000 & 0.767 & 0.526 & 0.279 \\
\hline $\mathrm{EV}$ & & & 1.70 & I & 2.23 & 1.60 & 1.36 & 1.45 & 3.05 & 2.24 & 1.99 & 1.33 & 1.02 & 1.66 & 2.08 & 1.41 & 1.77 & 1.61 & 0.84 & 0.96 \\
\hline L & . & & 0.014 & I & 0.000 & 0.026 & 0.103 & 0.063 & 0.000 & 0.000 & 0.002 & 0.118 & 0.466 & 0.019 & 0.001 & 0.079 & 0.009 & 0.025 & 0.730 & 0.540 \\
\hline & & & 2.29 & I & 1.54 & 1.20 & 1.28 & 1.43 & 1.74 & 1.40 & 1.63 & 1.07 & 1.09 & 1.16 & 1.40 & 0.96 & 1.86 & 1.11 & 0.99 & 0.98 \\
\hline & & & 0.000 & I & 0.006 & 0.141 & 0.075 & 0.020 & 0.001 & 0.027 & 0.002 & 0.344 & 0.309 & 0.197 & 0.025 & 0.578 & 0.000 & 0.273 & 0.515 & 0.539 \\
\hline & & & 287 & 123 & 42.4 & 38.2 & 0.05 & 15.9 & 1.94 & 39.5 & 108 & 9.70 & 0.58 & 3.81 & 5.26 & 19.9 & 56.9 & 64.9 & 4.14 & 0.51 \\
\hline & & & 0.000 & 0.000 & 0.000 & 0.000 & 0.818 & 0.000 & 0.166 & 0.000 & 0.000 & 0.002 & 0.448 & 0.053 & 0.024 & 0.000 & 0.000 & 0.000 & 0.044 & 0.477 \\
\hline I & $\mathrm{Cl}$ & 4 & 0.95 & 1.84 & 2.82 & 1.45 & 1.59 & 1.53 & 2.21 & 2.48 & 2.84 & 1.46 & 1.00 & 1.24 & 1.52 & 2.13 & 3.18 & 1.44 & 1.30 & 1.59 \\
\hline 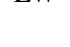 & 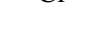 & 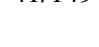 & 0.556 & 0.006 & 0.000 & 0.064 & 0.028 & 0.040 & 0.000 & 0.000 & 0.000 & 0.062 & 0.482 & 0.188 & 0.042 & 0.001 & 0.000 & 0.068 & 0.138 & 0.029 \\
\hline & & & 1.52 & 1.24 & 1.75 & 1.30 & 1.66 & 1.40 & 1.54 & 1.75 & 1.47 & 1.34 & 1.08 & 1.10 & 1.61 & 0.81 & 1.58 & 1.22 & 1.44 & 0.83 \\
\hline & & & 0.007 & 0.107 & 0.001 & 0.066 & 0.002 & 0.027 & 0.006 & 0.001 & 0.014 & 0.045 & 0.324 & 0.292 & 0.003 & 0.874 & 0.004 & 0.127 & 0.018 & 0.843 \\
\hline
\end{tabular}

${ }^{1}$ Significance of $F$ values with $p<0.05$ is given in bold.

modelled for wood samples containing several rings. These advantages can simplify modelling of final product properties [13].

Aknowledgements: This research was done while Miloš Ivković was a post-doctoral fellow with INRA, Centre de Recherches d'Orléans, France. He was supported by the two European Union projects: GENIALITY and GEMINI. The authors are grateful for their comments on early drafts to Dr Jugo Ilic and Dr Harry Wu of CSIRO, FFP, Australia.

\section{REFERENCES}

[1] Chambers J., Cleveland W., Kleiner B., Tukey P., Graphical methods for data analysis, Wadsworth, London, 1983.

[2] Corson S.R., Tree and fibre selection for optimal TMP quality, Appita J. 52 (1999) 351-357.

[3] Dutilleul P., Herman M., Avella-Shaw T., Growth rate effects on correlations among ring width, wood density, and mean tracheid length in Norway spruce (Picea abies), Can. J. For. Res. 28 (1998) $56-68$. 
[4] Fritts H.C., Tree Rings and Climate, Academic Press, New York, 1976.

[5] Gilchrist W.G., Statistical Modelling with Quantile Functions, Chapman \& Hall/CRC Press, New York, 2000.

[6] Jagels R., Telewski F.W., Computer-aided image analysis of tree rings, in: Cook E.R., Kairiukstis L.A. (Eds.), Methods of dendochronology: applications in the environmental sciences, Kluwer Academic Publishers, Boston, 1990.

[7] Karenlampi P., Effect of distributions of fibre properties on tensile strength of paper: A closed form theory, J. Pulp Pap. Sci. 21 (1995) $138-143$.

[8] Karian Z.A., Dudewicz E.J., Fitting statistical distributions: the Generalized Lambda Distribution and Generalized Bootstrap Methods, Chapman \& Hall/CRC Press, New York, 2000.

[9] Koubaa A., Koran Z., Effect of fibre properties on strength development of air dried and press dried spruce CTMP, in: Zhang S.Y. Gosselin R., Chauret G. (Eds.), Proceedings of the 26th Biannual Meeting of the Canadian Tree Improvement Association and International Workshop on Wood Quality (CTIA/IUFRO), Québec City, 1997, pp. VII 35-42.

[10] Koubaa A., Zhang T.S.Y., Makni S., Defining the transition from earlywood to latewood in black spruce based on intra-ring wood density profiles from X-ray densitometry, Ann. For. Sci. 59 (2002) 511-518.

[11] Larson P.R., Wood formation and the concept of wood quality, Yale University School of Forestry, Bulletin 74, 1969.

[12] Littell R.C., Milliken G.A., Stroup W.W., Wolfinger R., SAS System for Mixed Models, SAS Institute Inc., Cary, N.C., USA, 1996.

[13] Nepveu G., Timber management toward wood quality and end-product value: France's experience, in: Zhang S.Y., Gosselin R., Chauret G. (Eds.), Proceedings of the 26th Biannual Meeting of the Canadian Tree Improvement Association and International Workshop on Wood Quality (CTIA/IUFRO), Québec City, 1997, pp. IV 53-62.

[14] Parker M.L., Jozsa L.A., X-ray scanning machine for tree ring width and density analyses, Wood Fiber 5 (1973) 192-197.

[15] Rozenberg P., Cahalan C., Spruce and wood quality: genetic aspects (a review), Silvae Genet. 46 (1997) 270-279.

[16] Rozenberg P., Franc A., Mamdy C., Launay J., Scherman N., Bastien J.C. Genetic control of stiffness of standing Douglas fir; from the standing stem to the standardised wood sample, relationships between modulus of elasticity and wood density parameters, Part 2, Ann. For. Sci. 56 (1999) 145-154.

[17] Rozenberg P., Franc A., Chantre G., Baonza V., Indirect genetic selection of end-products wood properties: a method suitable for both tropical and temperate forest trees, S. Afr. For. J. 190 (2001) 99-104.

[18] Rozenberg P., Franc A., Bastien C., Cahalan C., Improving models of wood density by including genetic effect: a case study in Douglas fir, Ann. For. Sci., 58 (2001) 385-394.

[19] SAS Institute Inc., SAS/STAT ${ }^{\circledR}$ User's Guide, Version 6, 4th ed. Vols. 1 and 2, SAS Institute Inc., Cary, N.C., 1996.

[20] SAS Institute Inc., SAS/STAT ${ }^{\circledR}$ Software: Changes and Enhancements through Release 6.12, SAS Institute Inc., Carry, N.C., 1997.

[21] Statistical Sciences, S-PLUS Guide to Statistical and Mathematical Analysis, Version 3.2, Statistical Sciences, MathSoft Inc., Seattle, 1993.

[22] Taylor F.W., Wang E.I., Yanchuk A., Micko M.M., Specific gravity and tracheid length variation of white spruce in Alberta, Can. J. For. Res. 12 (1982) 561-566.

[23] Vargas-Hernandez J., Adams W.T. Genetic variation of wood density components in young coastal Douglas fir: implications for tree breeding, Can. J. For. Res. 21 (1991) 1801-1807.

[24] Venables W.N., Ripley B.D., Modern applied statistics with SPLUS, Springer-Verlag, New York, 1999.

[25] Wimmer R., Downes G.M., Evans R., High-resolution analysis of radial growth and wood density in Eucalyptus nitens, grown under different irrigation regimes, Ann. For. Sci. 59 (2002) 519-524.

[26] Worrall J., Interrelationships among some phenological and wood property variables in Norway Spruce, TAPPI J. 53 (1970) 58-63.

[27] Worrall J., Provenance and clonal variation in phenology and wood properties of Norway spruce, Silvae Genet. 24 (1975) 2-5.

[28] Zamudio F., Beattig R., Vergara A., Guerra F., Rozenberg F., Genetic trends in wood density and radial growth with cambial age in a radiata pine progeny test, Ann. For. Sci. 59 (2002) 541-549.

[29] Zobel B.J., Jett J.B., Genetics of wood production, SpringerVerlag, New York, 1995.

[30] Zobel B.J., van Buijtenen J.P., Wood variation: its causes and control, Springer-Verlag, New York, 1989. 